\title{
Organizational Structure: Influencing Factors and Impact on a Firm
}

\author{
Quangyen Tran ${ }^{1,2}$, Yezhuang Tian ${ }^{1}$ \\ ${ }^{1}$ School of Management, Harbin Institute of Technology, Harbin, China; ${ }^{2}$ National Economics University, Hanoi, Vietnam. \\ Email: yentq@neu.edu.vn
}

Received November $3^{\text {rd }}, 2012$; revised December $17^{\text {th }}, 2012$; accepted January $18^{\text {th }}, 2013$

Copyright (C) 2013 Quangyen Tran, Yezhuang Tian. This is an open access article distributed under the Creative Commons Attribution License, which permits unrestricted use, distribution, and reproduction in any medium, provided the original work is properly cited.

\begin{abstract}
The influence of certain factors on organizational structure has been in researchers' focus for years, together with their impact on the overall organizational efficiency. Many of these factors are from the environment where traditional view commonly divided into internal and external factors. This paper presents the findings of a study to evaluate the influencing factors and impact on organizational structure of a sample of firms located in Hanoi, Vietnam. Structured questionnaires were administered with respect to these factors. The variables studied were identified from among the factors considered in contingency theory and by incorporating elements of the strategic choice approach. After grouping the variables into two factors (related to external and internal respectively), the results revealed three groups of firms according to how they regarded the impact of these factors on organizational structures. In those groups that consider the variables of internal factors to be modifiers of structure the organizational structures are of the "complex classical" type, whereas simple forms predominate in the group that believes these variables do not modify their structure.
\end{abstract}

Keywords: Organizational Structure; Firm; Influencing Factors; Contingency; Resources

\section{Introduction}

Organizations are formed by groups of people with the purpose of achieving effects that one person cannot achieve individually. Better results are created as a consequence of organizational effect which directs organization to achieving some organizational goals [1]. Regarding the purpose of the organization's founding, they can be described as successful (profitable) or failure (nonprofitable) ones. To achieve these goals organizations create inner order and relations among organizational parts that can be described as organizational structure. All organizational parts together with relations and mechanisms of their coordination are important for proper functioning of any organization. Organizations are influenced by many factors which come from their dynamic surrounding or from the organization itself. Due to the static nature of organizational structure, it sometimes cannot meet requirements of efficiency and adoptability. Classics in the field of organization theory represented many different schools of influencing factors on organizational structure. Some believed that certain factors, such as size, environment, or technology, determined organizational structure. They argued that these factors imposed economic or other constrains on organizations that forced them to choose a certain structure over others. Organizational structure is partly affected by the firm's external environment [2-5]. Research suggested that firms organized to deal with reliable and stable market may not be as effective in a complex, rapidly changing environment $[6,7]$. The more certain the environment is, the more centralized hierarchy the firm's organizational structure may have, with formalized rules and procedures [5]. Organizations that operate with a high degree of environmental uncertainty may decentralize decisionmaking [8], relying on formal rules and policies [9], and flatten their hierarchies [10]. The influence of certain factors on organizational structure is traditionally divided into two main factors. These factors which determine the structure, aims and activities of the organization, can be grouped into external factors and internal factors [11]. External factors are those factors from the enabling environment which are not under the control of the organization but which affect its structure and development. These include economic factors which define the economic situation where production and processing take 
place (the market/industry); socio-economic factors that define the socio-economic context in which the organization operates; and political-administrative factors which define the legal boundaries and organizational options. Internal factors are those organizational characteristics which create a basis for measuring and comparing organizations. These include mission statement of the organization and organizational instruments.

\section{Literature Review}

\subsection{The Concept of Organizational Structure}

There are many different opinions and definitions on organizational structure. Structure in one sense is the arrangement of duties use for the work to be done. This is best represented by the organization chart [12]. In another sense, "structure is the architecture of business competence, leadership, talent, functional relationships and arrangement" [13]. Walton [14] identified structure as the basis for organizing, to include hierarchical levels and spans of responsibility, roles and positions, and mechanisms for integration and problem solving. Thompson [15] said that "structure is the internal differentiation and patterning of relationships". He referred to structure as the means by which the organization sets limits and boundaries for efficient performance by its members, by delimiting responsibilities, control over resources, and other matters. Kartz and Kahn [16] said that "structure is found in an interrelated set of events which return to complete and renew a cycle of activities." Jackson and Morgan [12] used a modified definition originally formulated by [17]. They defined structure "as the relatively enduring allocation of work roles and administrative mechanisms that creates a pattern of interrelated work activities and allows the organization to conduct, coordinate, and control its activities". Lawrence and Lorsch [5] describe structure as "the technique in which the organization is differentiated and integrated". Differentiation is related to the scope in which executives act quasi entrepreneurs, whereas integration is described in such a way that every member of the organization including managers will do their best to achieve organizational goals. Similarly, an organization is a set of elements in interaction, organized level and decision making units [18]. Identification of these elements has always been one of the most important issues facing organizational researchers.

According to Dictionary-Organizational behavioral [19], organizational structure is defined as "the established pattern of relationships among the components of parts of company (The way a company is set-up). They formally defined framework of an organization's task and authority relationships". Sablynski [20] succinctly defined organizational structure as "how job tasks are formally divided, grouped, and coordinated". Or- ganization structure indicates an enduring configuration of tasks and activities [21]. In other words, organiza- tional structure is a set of methods through which, the organization divided into distinct tasks and then create a harmony between different duties [22]. Underdown [23] said organizational structure "is the formal system of task and reporting relationships that controls, coordinates, and motivates employees so that they cooperate to achieve an organization's goals". Andrews [24] stated that organizational structure "consists of job positions, their relationships to each other and accountabilities for the process and sub-process deliverables". Organizational structure directs the competence of work, the enthusiasm of employees and coordination among the top management and subordinates for flow of plans and goals in the organization to sketch the future plans [25]. Organizational structure is a way responsibility and power are allocated, and work procedures are carried out, among organizational members [8,10,26-29]. Zheng, et al., [30] mentioned that the most important components of organizational structure include formalization, centralization, and control. Formalization measures the extent to which an organization uses rules and procedures to prescribe behaviour [31]. The nature of formalization is the degree to which the workers are provided with rules and procedures [32] that deprive versus encourage creative, autonomous work and learning. In organization with high formalization, there are explicit rules which are likely to impede the spontaneity and flexibility needed for internal innovation [33].

Centralization refers to the hierarchical level that has authority to make decision. If decisions are delegated to lower levels the organization is decentralized and if decision making power authority is kept at the top level it is centralized [34]. Centralization also creates a non-participatory environment that reduces communication, commitment, and involvement with tasks among participants [33]. Organizational control is a cycle that includes the three stages of target setting, measuring or monitoring and feedback. Control in the bureaucracy can consist of rules, standards, and internal procedures [34]. Developing and enforcing performance control and behaveioural prescriptions improve decisions and increases predictability of performance [35]. Chen and Huang [33] claimed that decentralized and informal structure will lead to higher performance. Also Germain et al., [35] studied the effect of structure on the performance mediating supply chain management and found that in stable environment, formal structure has a positive effect on the performance while in dynamic atmosphere negative effect is attained. Therefore, Zheng et al., [30] concluded that there is a negative effect of structure on organizational effectiveness. 
Researchers have argued that if organizational theory is to be relevant to practitioners, emphasis should be placed on organizational effectiveness and its influencing factors [36-40]. In the light of this argument, any meaningful impact of organizational structure on a firm should be measured in terms of the relationship with the firm's effective performance. In discussing the difficulties of determining organizational effectiveness, Bedeian [41] said, "Although effectiveness is a central theme in the study of organizations, it remains one of the most frequently cited yet least understood concepts in organization theory". Bedeian [41] continued to say that failing to consider organizations goals, characteristics, and constituents lead to faulty assumptions of performance. Once an organization decides how it wants its members to behave, what attitudes it wants to encourage, and what it wants its members to accomplish, it can design its structure and encourage the development of cultural values and norms to obtain these desired attitudes, behaviors, and goals [23]. Sablynski [20] found no relationship between employee performance and span of control, but higher levels of job satisfaction were evident in decentralized organizations because span of control portion of organizational structure defines the amount of employees an authority figure is responsible for. The span of control is expressed in one of two ways: a wide span of control where managers supervise many employees as well as a narrow span of control where managers supervise few employees [42]. Sablynski [20] says organizational structure decreases employee ambiguity and helps explain and predict behavior. Brown [43] believed the basis for organizational structure is alignment of the organization purpose with necessary resources. Companies that grow rapidly are those that make the best use of their resources, including management talent. As a company grows, the impact on the structure of the organization is significant. This can be especially true when the organization begins to expand to other geographic regions and the structure of the organization is spread out over many miles.

A company may start out small; however, as time goes by when more employees may be hired, it is necessary for the departmental managers to create a managerial structure. Additionally, an executive team may be required to run the various aspects of the business, and there may be the need for middle managers who would report to the managers. Penguin [44] stated that, organizational effectiveness and its relation to structure is determined by a fit between information processing requirements so people have neither too little nor too much irrelevant information. However, the flow of information is essential to an organization's success [45]. The organization's structure should be designed to ensure that individuals and departments that need to coordinate their efforts have lines of communication that are built into the structure. Companies may use various organizational structures for communication purposes. Large companies have many levels of management. Therefore, the most effective way to communicate is from top of the organization down. Executives create certain operational procedures which they communicate to directors and managers. Managers, in turn, explain these operational procedures to subordinates or hourly employees. Wolf [13] said structure has a direct effect on the success of an organization operational strategy. "Good organization structure influences the execution behaviors of a company. Structure not only shapes the competence of the organization, but also the processes that shape performance". Therefore, Clemmer [46] supported the idea that organizational structure shapes performance: Good performers, in a poorly designed structure, will take on the shape of the structure. Many organizations induced learned helplessness. People in them become victims of "the system". This often comes from a sense of having little or no control over their work processes, policies and procedures, technology, support systems and the like. These feelings are often amplifies by a performance management system that arbitrarily punishes people for behaving like the system, structure or processes they have been forced into. Walton [14] tied structure to effectiveness, asserting that management restructuring is designed to increase not only the efficiency but also the effectiveness of the management organization. Walton [14] associated quicker responses to problems, increased unity of functions, coherent and consistent priorities, enhanced abilities, and career satisfaction with the performance benefits of structural alignment. A given structural alignment can only emphasize a few of the interdependencies among activities. Therefore, appropriate structures must ensure that the most important types of coordination occur [14]. Organizational structure includes decision-making, customer's needs, and harnessing experience [8,10,27,29,36]. Decision-making authority is influenced by organizational structure. In decentralized structure front-line employees are often empowered to make on the-spot decisions to meet customer needs [47]. An example of this is the clothing store clerk who is able to offer a refund or exchange without management's authorization. In central structures, low-level employees pass critical information to managers, who make the majority of decisions. Organizational structure has an impact in harnessing experience of employees [45]. Companies may arrange their companies by specific functions, such as marketing, accounting, finance and engineering. The purpose of grouping departments by function is to use the experience of groups to accomplish tasks and projects.

A certain synergism exists when skilled employees of 
similar talents work together as a whole. For example, marketing and advertising managers can better evaluate the potential success of a new product introduction as a group.

\subsection{The Influencing Factors}

In this study the influencing factors we considered are among the factors described by contingency theory, and by incorporating elements of the strategic choice approach. Many authors have noted the impact of these factors and elements on organizational structures. Indeed, in response to different environmental circumstances, the organizational structure is conditioned by decisions regarding the internal organizational level in general and designed variables in particular (centralization, formalization and control), both of which are governed by organizational leaders' perceptions and preferences in response to external factors. The factors taken into account in this study are:

\subsubsection{Decentralization of Decision Making}

Menon and Varadarajan [48] maintained that, centralization fosters a hierarchical organizational structure whereby ultimate power and decision-making is concentrated at the top rather than shared with lower levels of the organization. Hollenbeck [49] argued that one of the most widely-studied dimensions of organizational structure is centralization, which deals with the aspect of vertical structure and refers to the degree to which decisionmaking authority and responsibility for coordination resides at the top of the organizational chart as opposed to being distributed throughout lower levels.

\subsubsection{Customer Interaction}

Auh and Mengue [50] attempted to relate this factor to centralization and concluded that as customer interaction demands a broad focus of authority and organizationwide participation, it requires more decentralized and less hierarchical structures. Similarly, Jabnoun [51] sought to identify the organizational structure that supports the implementation of customer interaction total quality management. The results show that the dimensions of process network and organic structure support the implementation of customer-interacted total quality management, while risk aversion, mechanistic structure and complexity impede it.

\subsubsection{Value of Innovation}

Selto et al., [52] addressed the issues of the best "fit" of organizational structure and controls for just-in-time and total quality management.

\subsubsection{Marketing Considerations}

Sundaram and Black [53] argued the need for better and newer applications of organizational theories to the study of multinational enterprises.

\subsubsection{Intensifying Competition}

Vroom [54] attempted to elucidate how organizational design characteristics are related to the competitive behavior of firms. Although previous research suggests that in cases of strategic substitutability, firms tend to choose organizational structures and compensation systems that commit the firm to behaving aggressively in the product market, thus reducing firm and industry profits, he argued that simultaneous determination of organizational structure and compensation systems may enable firms to tacitly collude and achieve the perfectly collusive outcome despite the non-cooperative setting.

\subsubsection{Liberalization of the Economy}

Snow et al., [55] proposed a network organization structure as an organizational response to a context of globalization, technology transfer and technological change, deregulation, changing workforce demographics, manufacturing advances, faster, lower cost communications and greater social and political freedom.

This paper integrates many business management literatures to understand the influencing factors and impact of organizational structure in an organization. Therefore, the paper develops a research frame work that examines the concept of organizational structure and it influencing factors on selected firms in Hanoi, Vietnam.

\section{Methodology}

The methodology used in this study was qualitative. Therefore, in order to provide an independent source of information about the sample firm's degrees of organizational development, we used email survey to collect information about these firms. A sample size of fifty six firms located in Hanoi, Vietnam was used in this study. The questionnaire used in the survey consisted of questions sought to obtain data on the use of the different technologies, employee training and the number of hierarchical levels. Specifically, firms were asked to assess how the variables defined above (see also Table 1) had modified the organizational structure, rating the degree of modification on a Likert scale from 0 to 10 , where 0

Table 1. Results of exploratory factor analysis applied to the variables studied.

\begin{tabular}{ccc}
\hline Items & First Factor & Second Factor \\
\hline Decentralization of decision making & 0.981 & 0.181 \\
Marketing considerations & 0.962 & 0.153 \\
Liberalization of the economy & 0.874 & 0.432 \\
Customer interaction & 0.110 & 0.816 \\
Intensifying competition & 0.298 & 0.801 \\
Value of innovation & 0.500 & 0.600 \\
\hline
\end{tabular}


meant "not modified at all" and 10 meant" completely changed". The data was analyzed using multivariate analysis in order to understand the behavior of the variables studied. Two analyses were applied: 1) an exploratory factor analysis that allowed the variables to be grouped in a theoretical rather than an observable factor; and 2) a cluster analysis that enabled groups of firms to be created that were related to organizational structures. Both analyses were described below.

\subsection{Exploratory Factor Analysis}

The aim of the exploratory factor analysis was to group the variables into a few latent factors, in which the most closely related variables are linked together in the same factor.

We applied two tests of the correlation matrix: 1) Bartlett's test of sphericity (measures the null hypothesis that the there is a linear dependence between two variables) and 2) the Kaiser-Meyer-Olkin test (a statistic which indicates the proportion of variance in a sample). Both tests are measures of sampling adequacy to validate the use of factor analysis. Bartlett's test with the value of $\chi^{2}=364.74$ (significance level: 0.000 ) confirmed the linear dependence between the variables, and thus the analysis could continue; the Kaiser-Meyer-Olkin (KMO) test with a value of 0.931 , also confirmed that factor analysis was likely to generate satisfactory results [56]. Two factors were extracted from the analysis. The KMO criterion was used to retained only those factors that represented Eigen values of one or greater. These first two factors accounted for $93.06 \%$ of the initial variance, which represented a good proportion of information. Applying the method of Varimax rotation, loadings were obtained for each factor for each of the variables (Table 1). The two factors obtained were then used as inputs for a cluster analysis, which aims to group firms with a similar within-group (but different between-group) behavior. This analysis is described below.

\subsection{Cluster Analysis}

This analysis sought to classify the firms according to their orientation, that is, more strategic or more customer-oriented. The method employed was hierarchical [57] and used distances to measure the similarity or dissimilarity between individuals. The method used to obtain the groups was that of Ward [58], this being one of the most robust methods and one that is able to create homogeneous groups with minimum variance. This resulted to a three-group classification. The model's goodness-of-fit was measured through the mean square of the eta, $\eta^{2}$ as $0.768\left(y^{2}=0.768\right)$. To complete the description of each group by adding information about its organizational structure, a contingency table was drawn up to determine whether there was a relationship between groups and structures. Structures were grouped into three general forms: simple (linear, functional, adhocratic), complex classical (line-functional, divisional, in matrix, collegial) and complex new (federal, in clover, network). The contrast was statistically significant at the $90 \%$ level, with $\mathrm{p}$-value $=0.113$.

\section{Results and Discussion}

The first factor represents the variables that are more closely related to internal factors, while the second concerns issues related to customer interaction. In the first factor all variables have a high loadings-decentralization of decision making, marketing considerations, and liberalization of the economy. This factor measures whether these variables linked to internal factors modify in some way the structure of the organization. In the second factor the contributions were lower, and the biggest difference concerned the variable "value of innovation" which only makes a minor contribution. The two variables are related to customer interaction, since greater competition to meet customer expectations will help to avoid losing a market share. Value of innovation is important to obtain the product or service that satisfies customers.

The results of cluster analysis from the inputs of the two factors revealed three groups of firms as shown in Table 2.

\subsection{Group 1}

This group had twenty four firms and it is the largest group detected $(42.90 \%$ of the sample). The firms from this group consider that variables related to internal factors have not modified their organizational structures; external factors such as customer interaction variable was also regarded not to have modified structures, although to a lesser extent. The members of this group mostly present simple structures ( $48 \%$ of firms' organization), complex new forms (31\% of firms' organization) and complex classical forms ( $21 \%$ of firms' organization) are the least frequent.

\subsection{Group 2}

Comprised seventeen firms, representing $30.36 \%$ of the sample, members of this group rate both factors almost

Table 2. Description of groups.

\begin{tabular}{|c|c|c|c|c|c|c|}
\hline \multirow{2}{*}{$\begin{array}{l}\text { Firm } \\
\text { Groups }\end{array}$} & \multirow{2}{*}{ Members } & \multirow{2}{*}{$\begin{array}{l}\text { (Internal } \\
\text { Factors) }\end{array}$} & \multirow{2}{*}{$\begin{array}{c}\text { (External } \\
\text { Factors) }\end{array}$} & \multicolumn{3}{|c|}{$\begin{array}{c}\text { Main organizational } \\
\text { structures }\end{array}$} \\
\hline & & & & Simple & Classical & New \\
\hline Group 1 & 24 & -1.24 & -0.14 & $48 \%$ & $21 \%$ & $31 \%$ \\
\hline Group 2 & 17 & 1.08 & 1.00 & $11 \%$ & $53 \%$ & $36 \%$ \\
\hline Group 3 & 15 & 0.81 & -0.89 & $23 \%$ & $70 \%$ & $7 \%$ \\
\hline
\end{tabular}


at the same level in terms of modifying structure. For these firms, internal factors and external factors have both changed their structure. The predominant organizational form in this group is complex classic $(53 \%$ of firms' organization). Complex new structures are present in $36 \%$ of firms' organization, while simple forms are the least common ( $11 \%$ of firms' organization).

\subsection{Group 3}

This is the smallest group obtained and it includes fifteen firms $(26.79 \%$ of the sample). In this group both factors were rated similarly, although for internal factors were rated as having changed their organizational structures, whereas external factors were not seen as modifiers these firms. In this group only one firm had the complex new form $(8 \%)$, whereas simple structures were present in $23 \%$ of the firms' organization and the complex classic form in $70 \%$.

The above three groups of firms were identified according to the different ways in which they regarded impact of variables that are influencing factors of change in organizational structures. These variables are grouped into two factors, first related to internal factors (factors which are from the enabling environment under the control of the firm) and the second associated to external factors (those factors from the enabling environment which are not under the control of the firm). Results of exploratory factor analysis applied to the variables studied showed that "decentralization of decision making" makes the largest contribution to the first factor. This outcome reinforces Hollenbeck's [49] argument that such a variable as received the most attention in the study of organizational structures. The second factor emphasized customer interaction, which according to Auh and Mengue [50] was negatively related to the first variable factor. It was the variable that made the greatest contribution. With respect to the resulting groups, the first was the largest, comprising twenty four firms. These firms were simple organizational structures which believed that internal factors did not change their structure. The second group structure consisted of seventeen firms, the majority of which had a complex classical structure; these firms did consider that both internal and external factors modified their structure. The third group of fifteen firms, mostly with a complex classical structure also considered that internal factors modified their organizational structure.

A well designed organizational structure promotes success. Businesses require structure to grow and be profitable. Designing an organization structure helps top management identify talent that needs to be added to the company. If an organizational structure does not fit the company's goals and objectives, it can hinder coopera- tion therefore, the completion of tasks will result in slower cycle times and inefficient use of resources.

\section{Conclusion}

In this paper we presented the findings of a study to evaluate the influencing factors and impact on organizational structure of a sample of firms located in Hanoi, Vietnam by using structured questionnaires with respect to these factors. It was found out that in those groups that consider the variables of internal factors to be modifiers of structure, the organization al structures are of the "complex classical" type, where as simple forms predominate in the group that believes these variables do not modify their structures. Accordingly, depending on the presence, direction and intensity of the forces exerted by various environmental dimensions and of decisions on how to manage the work, the division of activities in which firms were committed will be determined toward the production of different organizational forms. That is why studying influencing factors on organizational structure is one way to improve organizational effects on firms. The study focuses on six influencing factors (internal and external) on organizational structure. Therefore, for future research, a larger sample, including more variables related to confidence in the environment is recommended.

\section{Acknowledgements}

We wish to thank all the firms in Hanoi, Vietnam, that collaborated in the study.

\section{REFERENCES}

[1] B. Kristina, et al., "Impact of ICT on the organizational Structure Elements: Case of the Varazdin County," Pavlinska 2, 42000 Varazdin, Croatia.

[2] L. J. Bourgeois, D. W. McAllister and T. R. Mitchell, "The Effects of Different Organizational Environments upon Decisions about Organization Structure," Academy of Management Journal, Vol. 21, No. 3, 1978, pp. 508514. doi: $10.2307 / 255732$

[3] R. B. Duncan, "Characteristics of Organizational Environments and Perceived Environmental Uncertainty," Administrative Science Quarterly, Vol. 17, No. 3, 1972, pp. 313-327. doi: $10.2307 / 2392145$

[4] L. G. Hrebiniak and C. C. Snow, "Industry Differences in Environmental Uncertainty and Organizational Characteristics Related to Uncertainty," Academy of Management Journal, Vol. 23, No. 4, 1980, pp. 750-759. doi: $10.2307 / 255561$

[5] P. R. Lawrence and J. W. Lorsch, "Organization and Environment," Irwin, Homewood, 1967.

[6] L. Gordon and V. K. Narayanan, "Management Accounting Systems, Perceived Environmental Uncertainty, and Organizational Structure: An Empirical Investigation," 
Accounting, Organizations and Society, Vol. 9, No. 1, 1984, pp. 33-47. doi:10.1016/0361-3682(84)90028-X

[7] R. E. Spekman and L. W. Stern, "Environmental Uncertainty and Buying Group Structure," Journal of Marketing, Vol. 43, No. 2, 1979, pp. 54-64. doi: $10.2307 / 1250741$

[8] R. W. Ruekert, et al.," The Organization of Marketing Activities: A Contingency Theory of Structure and Performance," Journal of Marketing, Vol. 49, No. 1, 1985, pp. 13-25. doi:10.2307/1251172

[9] B. J. Jaworski, "Toward a Theory of Marketing Control: Environmental Context, Control Types, and Consequences," Journal of Marketing, Vol. 52, No. 3, 1988, pp. 23-29. doi: $10.2307 / 1251447$

[10] R. E. Walton, "From Control to Commitment: Transforming Work Force Management in the US," In: K. Clark, R. Hayes and C. Lorenz, Eds., The Uneasy Alliance: Managing the Productivity-Technology Dilemma, Harvard Business School Press, Boston, 1985, pp. 237265.

[11] "The Role of Organizational Structure in an Organization," 2012. http://www.fao.orgdocrep/005

[12] J. H. Jackson and C. P Morgan, "Organization Theory," 2nd Edition, Prentice Hall, Upper Saddle River, 1982.

[13] D. Wolf, "Execution and Structure," 2002. http://www.dewarsloan.com/workin\%20papers-execution $\% 20$ and $20 \%$ structure.html

[14] R. E. Walton, "A Vision-Led Approach to Management Restructuring," Organizational Dynamics, Vol. 14, No. 4, 1986, pp. 5-17.

[15] J. D. Thompson, "Organization in Action," McGraw-Hill, New York, 1966.

[16] D. Kartz and R. L. Kahn, "The Social Psychology of Organizing," 2nd Edition, Wiley, New York, 1978.

[17] J. Child, "Organizational Structure, Environment and Performance: The Role of Strategic Choice," Sociology, Vol. 6, No. 1, 1972, pp. 1-22. doi: $10.1177 / 003803857200600101$

[18] P. D. Martinelli, "Systems Hierarchies and Management," Systems Research and Behavioral Science, Vol. 18, No. 1, 2001, pp. 68-82.

[19] “Dictionary-Organizational Behavioral," 2012. http://www.ivey.uwo.ca/intlstudentsdictionary/OBdic.html

[20] C. J. Sablynski, "Foundation of Organizational Structure," 2012. http://www.csus.edu/indiv/s/sablynskic/ch.14.html

[21] J. E. Skivington and R. L. Daft, "A Study of Organizational Frame Work and Process Modalities for the Implementation of Business-Level Strategic Decisions," Journal of Management Study, Vol. 28, No. 1, 1991, pp. 4568.

[22] H. Mintzberg, "The Structuring of Organizations," Prentice Hall, New Jersey, 1979.

[23] R. Underdown, “Organizational Structures," 2012. http://dept.lamar.edu/industrial/underdown/org_mana/org/ org_structure-George.html
[24] D. C. Andrews, "Is There an Organizational Structure for Our Reengineering Business Operation?" Enterprise Reengineering, 2012. http://www.efenselink.mil/c3ibpr/prcd 5280.html

[25] S. K. Herath, "A Framework for Management Control Research," Journal of Management Development, Vol. 26, No. 9, 2007, pp. 895-915. doi: $10.1108 / 02621710710819366$

[26] P. M. Blau, "Decentralization in Bureaucracies," In: M. N. Zald, Ed., Power in Organizations, Vanderbilt University Press, Nashville, 1970, pp. 150-174.

[27] R. Dewar and J. Werbel, "Universalistic and Contingency Predictions of Employee Satisfaction and Conflict," Administrative Science Quarterly, Vol. 24, No. 3, 1979, pp. 426-448. doi:10.2307/2989921

[28] R. Germain, "The Role of Context and Structure in Radical and Incremental Logistics Innovation Adoption," Journal of Business Research, Vol. 35, 1996, pp. 117-127. doi:10.1016/0148-2963(95)00053-4

[29] D. Gerwin and H. Kolodny, "Management of Advanced Manufacturing Technology: Strategy, Organization, and Innovation,” Wiley/Interscience, New York, 1992.

[30] W. Zheng, B. Yang and G. N. Mclean, "Linking Organizational Culture, Strategy and Organizational Effectiveness; Mediating Role of Knowledge Management," Journal of Business research, Vol. 63, No. 7, 2010, pp. 763771. doi:10.1016/j.jbusres.2009.06.005

[31] C. C. Liao et al., "How Knowledge Management Mediates the Relation between Environment and Organizational Structure," Journal of Business Research, Vol. 64, No. 7, 2011, pp. 728-736. doi:10.1016/j.jbusres.2010.08.001

[32] A. Y. Nahm, et al., "The Impact of Organizational Structure on Time-Based Manufacturing and Plant Performance," Journal of Operations Management, Vol. 21, No. 3, 2003, pp. 281-306. doi:10.1016/S0272-6963(02)00107-9

[33] C. J. Chen and J. W. Huang, "How Organizational Climate and Structure Affect Knowledge Management, The Social Interaction Perspective," International Journal of Information Management, Vol. 27, No. 2, 2007, pp. 104118. doi:10.1016/j.ijinfomgt.2006.11.001

[34] O. C. Ferrell and S. J. Skinner, "Ethical Behavior and Bureaucratic Structure in Marketing Research Organizations," Journal of Marketing Research, Vol. 25, No. 1, 1988, pp. 103-109. doi:10.2307/3172930

[35] R. Germain, et al., "Supply Change Variability, Organizational Structure and Performance: The Moderating Effect of Demand Unpredictability," Journal of operations management, Vol. 26, No. 5, 2008, pp. 557-570. doi:10.1016/j.jom.2007.10.002

[36] F. Damanpour, "Innovation Type, Radical Ness, and the Adoptive Process," Communication Research, Vol. 15, No. 5, 1988, pp. 545-567. doi:10.1177/009365088015005003

[37] K. J. Klein and J. S. Sorra, "The Challenge of Innovation Implementation," Academy of Management Review, Vol. 21, No. 4, 1996, pp. 1055-1080.

[38] J. L. Cheng and W. Mckingley, "Toward an Integration of 
Organization Research and Practice: A Contingency Study of Bureaucratic Control and Performance in Scientific Settings," Administrative Science Quarterly, Vol. 28, No. 1, 1983, pp. 85-100. doi:10.2307/2392388

[39] J. Hage, "Theories of organization," Wiley, New York, NY, 1980.

[40] R. E. White and R/G. Hamermes, "Toward a Model of Business Unit Performance: An Integrative Approach," Academy of Management Review, Vol. 6, No. 2, 1981, pp. 213-223.

[41] A. G. Bedeian, "Contemporary Challenges in the Study of Organization," Journal of Management, Vol. 12, No. 2, 1986, pp. 185-201.

[42] “What Impacts Organizational Structure?” 2012. http://www.ehow.com/facts_515

[43] J. J. Brown, "Flattening the Organizational Hierarchy of the Fairfax County, Virginia Fire and Rescue Department," Executive Fire Officer Program, National Fire Academy, Emmetsburg, Maryland, 1995.

[44] D. Penguin, "Fundamentals of Organizational Structure," 2003.

http://www.up.univ-mrs.fr/ wlag/ea/gmba/orgthe/topic2. html

[45] “The Importance of a Good Organizational," 2012. http://smallusiness.chron.com/importance-goodorganizati onal-srtucture

[46] J. Clemmer, "Organization Structure Limits or Liberates Highperformance," 2003. http://www.clemmer.net/excerpts/ph_orglimits.html

[47] "What are the Benefits of Organiaztional," 2012. http://www.ehow.com/list_6532

[48] A. Menon and P. Varadarajan, "A Model of Marketing Knowledge Use Within Firms," Journal of Marketing, Vol. 56, No. 4, 1992, pp. 53-71. doi:10.2307/1251986
[49] J. Hollenbeck, "A Structure Approach to External and Internal Person-Team Fit, Applied Psychology," An International Review, Vol. 49, No. 3, 2000, pp. 534-549.

[50] S. Auh and B. Mengue, "Performance Implications of the Direct and Moderating Effects of Centralization and Formalization on Customer Orientation," Industrial Marketing Management, Vol. 36, No. 8, 2007, pp. 1022-1034. doi:10.1016/j.indmarman.2006.02.010

[51] N. Jabnoun, "Organizational Structure or Customer-Oriented TMQ: An Empirical Investigation," The TMQ magazine, Vol. 17, No. 3, 2005, pp. 226-236.

[52] Selto, et al., "Assessing the Organizational Fit of a Just-in-Time Manufacturing System-Testing Selection, Interaction and Systems Models of Contingency Theory," Accounting, Organizations and Society, Vol. 20, No. 7-8, 1995, pp. 665-684. doi:10.1016/0361-3682(95)00022-2

[53] A. Sundaram and J. Black, "The Environment and Internal Organization of Multination-Enterprises," Academy of Management Review, Vol. 17, No. 4, 1992, pp. 729-757.

[54] G. Vroom, "Organizational Design and the Intensity of Rivalry," Management Science, Vol. 52, No. 11, 2006, pp. 1689-1702. doi:10.1287/mnsc. 1060.0586

[55] Snow, et al., "Managing 21st Century Network Organizations," Organizational Dynamics, Vol. 20, No. 3, 1992, pp. 4-20. doi:10.1016/0090-2616(92)90021-E

[56] B. Visauta, "Analisis Estdistico con SPSS Para Windows," McGraw Hill, Madrid, 1998.

[57] S, Johnson, "Hierarchical Clustering Schemes," Psychometrika, Vol. 32, No. 3, 1967, pp. 241-254. doi:10.1007/BF02289588

[58] J. Ward, "Hierarchical Grouping to Optimize an Objective Function," Journal of the American Statistical Association, Vol. 58, No. 301, 1963, pp. 236-244. doi:10.1080/01621459.1963.10500845 